\title{
Master and commander: continued expression of Prox 1 prevents the dedifferentiation of lymphatic endothelial cells
}

\author{
M. Gabriele Bixel and Ralf H. Adams ${ }^{1}$ \\ Max-Planck-Institute for Molecular Biomedicine, Department of Tissue Morphogenesis, and University of Münster, Faculty \\ of Medicine, Münster D-48149, Germany
}

Cell differentiation occurs mostly during a specific developmental time window and is irreversible. The homeobox-containing transcription factor Prox1 is a master regulator of lymphatic endothelial cell differentiation in the embryo. A study by Johnson et al. (pp 3282-3291) published in this issue of Genes \& Development now shows that continued expression of Prox1 is required to maintain lymphatic endothelial cell identity even in adult mice. These findings indicate that Prox1 is essential for the differentiation and function of the lymphatic vasculature throughout life.

Endothelial cells (ECs) form two highly branched, treelike tubular networks in the vertebrate body, the blood vasculature and the lymphatic vasculature, which have distinct functional roles and morphological features. Blood vessels carry circulating blood through arteries into extensive capillary beds, the sites where gases, nutrients, and waste products are exchanged, and back into veins. In contrast, lymphatic vessels form a blind-ended system that drains protein-rich liquid, the lymph, through a network of distal capillaries (also known as terminal or initial lymphatics), larger collecting ducts and, finally, the thoracic duct into the venous system (Fig. 1; Alitalo et al. 2005; Cueni and Detmar 2006; Adams and Alitalo 2007). While the ECs of blood vessels (BECs) are tightly sealed to each other by continuous junctions formed by VE-Cadherin and other adhesion molecules, the ECs of lymphatic capillaries have discontinuous button-like junctions surrounding small intercellular openings, which are thought to facilitate the entry of liquid and immune cells from the surrounding tissue (Dejana 2004; Baluk et al. 2007). Tightly associated pericytes form cell-cell contacts with BECs and thereby

[Keywords: Lymphatic endothelial cells; blood endothelial cells; lymphangiogenesis; reprogramming; Prox1; siRNA]

${ }^{1}$ Corresponding author.

E-MAIL ralf.adams@mpi-muenster.mpg.de; FAX 49-251-70365-499. Article is online at http://www.genesdev.org/cgi/doi/10.1101/gad.1751908. stabilize blood vessel capillaries, reduce leakage, and prevent hemorrhaging, while terminal lymphatics are completely devoid of such supporting cells. Only lymphatic collecting ducts are sparsely covered by smooth muscle cells (SMCs), a different type of supporting cell in the vasculature, which promote slow flow with peristaltic contractions (Alitalo et al. 2005; Adams and Alitalo 2007). Numerous flap-like valves prevent the backflow of lymph toward the more distal lymphatic structures, and are essential for efficient drainage (Fig. 1). The specialization of blood vessels and lymphatic vessels and of the various subdomains within these endothelial networks are reflected by distinct gene expression profiles and signaling pathways (Fig. 2). For example, arterial ECs express a multitude of markers that are largely or entirely excluded from the venous or lymphatic endothelium (Lamont and Childs 2006; Adams and Alitalo 2007). The glycoprotein LYVE-1 is not only restricted to lymphatic ECs (LECs) but is also predominantly confined to the terminal capillaries within the lymphatic tree (Makinen et al. 2005; Baluk and McDonald 2008). Among the molecular markers that can be used to distinguish BECs and LECs, the homeobox-containing transcription factor Prox1 (prospero-related homeobox 1) is of particular importance. Proxl is present in all nuclei throughout the lymphatic endothelium, and this pattern of expression is actually the earliest sign of lymphatic development when the first few LECs differentiate from BECs within a section of the cardinal vein (Wigle and Oliver 1999; Wigle et al. 2002).

\section{Prox1-master regulator of LEC differentiation}

Lineage tracing experiments have demonstrated that lymphatic ECs in the mouse are derived from venous ECs during embryonic development (Srinivasan et al. 2007). A cluster of ECs in the cardinal vein start to express Prox1, leave the vessel and migrate into the adjacent tissue and form the first primitive lymphatic structures (Wigle and Oliver 1999; Wigle et al. 2002). Signal- 

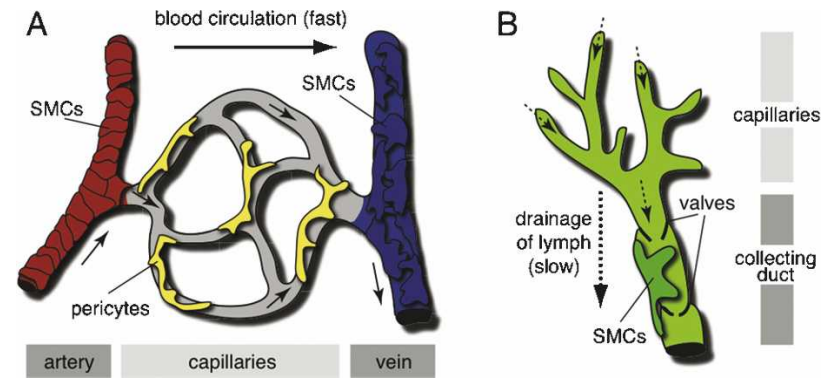

Figure 1. Morphological features of blood vessels and lymphatic vessels. (A) Schematic representation of the blood vessel network, which consists of arteries, capillaries and veins. Vascular SMCs cover larger calibre blood vessels, particularly arteries and veins, while pericytes tightly associate with the endothelium of capillary beds. (B) Blind-ended capillaries-i.e., initial lymphatics-enable the uptake of protein-rich liquid and cells into the lymphatic network. The unidirectional drainage of lymph is facilitated by flap-like valves and SMCs that are characteristic for collecting ducts. The flow of lymph is slow (dotted arrows), whereas circulation throughout blood vessel is generally fast despite significant local differences.

ing by vascular endothelial growth factor C (VEGF-C) and the receptor VEGFR3/Flt4, a receptor tyrosine kinase expressed by LECs, provides an essential chemoattractive signal for this first migration and is a critical regulator of subsequent lymphangiogenic growth (Veikkola et al. 2001; Karkkainen et al. 2004). Proxl is not only required for VEGFR3 expression in these first lymphatic ECs but the transcription factor is a much more general master regulator of LEC differentiation. Lymphatic differentiation and markers such as LYVE-1 or the chemokine CCL21 are down-regulated and a lymphatic system fails to form in Prox1-deficient embryos (Wigle et al. 2002). Overexpression of Proxl in cultured BECs upregulates the expression of many LEC markers while many BEC-specific genes get suppressed (Hong et al. 2002; Petrova et al. 2002). Recently, the nuclear orphan receptor NR2F2 (nuclear receptor subfamily 2), also known as COUP-TFII, was identified as a coregulator of Prox 1 in LEC differentiation (Lee et al. 2008). It is already known that NR2F2/COUP-TFII is an important regulator of venous BEC differentiation (Fig. 2; You et al. 2005), and its role in LECs may be a legacy of the venous origin of the lymphatic endothelium.

\section{LECs are reprogrammed in the absence of Prox1}

During organogenesis, the precursors of most cell types reach certain branch points at which their differentiation can be directed toward one or the other fate in response to changes in the gene expression profile, which are triggered in a cell-autonomous fashion by transcriptional regulators, by instructive signals from the local tissue environment, or a combination of both. A series of such fate decisions will determine the final outcome of a cell differentiation cascade and, typically, the result will be irreversible. The previously known data on Proxl func- tion indicated the transcription factor plays an essential but potentially transient role as a binary switch during LEC differentiation in the embryo (Wigle and Oliver 1999; Wigle et al. 2002). It was also clear that Prox1 expression in lymphatics persists into postnatal life, and a conspicuous down-regulation of Proxl in the defective lymphatics of some mutant mouse models had been observed (Wilting et al. 2002; Odaka et al. 2006; Backhed et al. 2007; Baluk and McDonald 2008). However, the relevance of these findings remained unclear. In this issue of Genes \& Development, a study led by Guillermo Oliver (Johnson et al. 2008) shows that the continued expression of Prox 1 is required to maintain LEC differentiation throughout life. Down-regulation of Proxl with inducible loss-of-function genetics in embryonic, postnatal, or adult mice leads to severe defects in the lymphatic vasculature and, persistently, mutant lymphatics vessels lose the expression of LEC markers and acquire ectopic markers characteristic for BECs. Prox1 mutant lymphatic vessels also acquire morphological features characteristic for normal blood vessels but not lymphatics, such as the presence of blood cells, connection to the blood circulation, and coverage by pericyte-like cells. The typical button-like organization of junctions, visu-

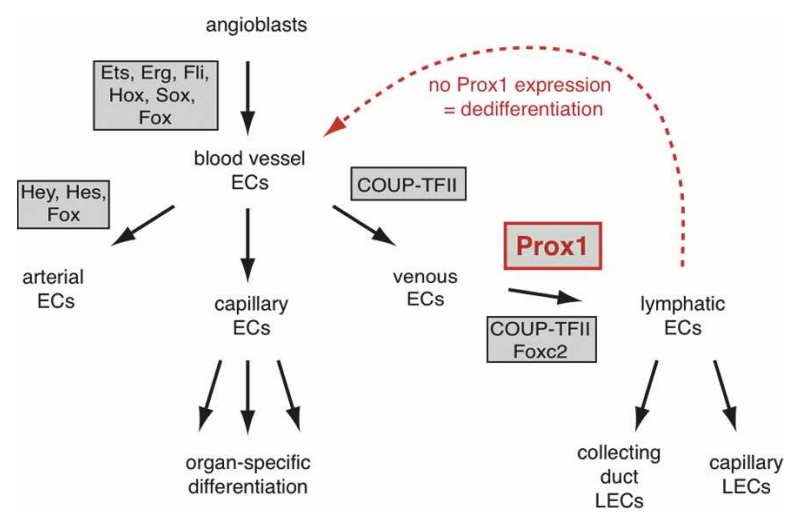

Figure 2. Transcriptional program of EC differentiation. Fox and Ets family transcription factors and Erg (Ets-related gene) play major roles in the differentiation of angioblast precursors and the generation of ECs (Dejana et al. 2007). Fli-1 and members of the Hox and Sox families are other factors controlling the endothelial expression profile (Dejana et al. 2007). The Notch pathway and downstream basic helix-loop-helix (bHLH) proteins of the hairy/enhancer-of-split-related transcription factor family (named Hey and Hes in mammals) control the differentiation of arterial ECs (Fischer et al. 2004; Roca and Adams 2007). Contribution of the forkhead box transcription factors FOXC1 and FOXC2 to arterial differentiation has been reported (Hayashi and Kume 2008). Capillary beds acquire organ-specific specialization but the underlying regulatory mechanisms are largely unknown. Expression of NR2F2/COUP-TFII in the venous endothelium suppresses Notch pathway genes and arterial differentiation (You et al. 2005). COUP-TFII and Foxc2 contribute to LEC differentiation (Seo et al. 2006; Lee et al. 2008), a process that critically relies on the master regulator Prox1 (red). Without Prox1, LECs acquire BEC features (red arrow) but it is not clear whether these cells have a venous or intermediate, poorly specified identity. 
alized with the junctional marker VE-Cadherin, is also lost in Prox 1 lymphatic vessels. However, a blood vesselstyle zipper-like pattern is not obtained in this case, suggesting that the compromised vascular identity of mutant lymphatics is perhaps incompatible with normal EC-EC interactions. The key finding made by Johnson et al. (2008)-i.e., that the maintenance of lymphatic identity requires constant activity of Proxl-can be reproduced in vitro. siRNA-mediated knockdown of Prox1 in primary human lymphatic ECs causes the loss of LEC markers and the ectopic expression of BEC markers.

\section{LEC plasticity in health and disease}

Endothelial tubules are thought to form fairly stable networks, and some larger vessels obviously stay in place for life. At the same time, ECs retain the capacity for growth and reorganization of the vessel network in response to altered tissue requirements, damage, or certain disease conditions. But this phenotypic plasticity is not known to involve the reprogramming of ECs, and therefore it is rather puzzling that LEC identity is so strictly coupled to Prox1 expression. In the embryo, arterial and venous BEC identities appear to be interconvertible to some extent (Moyon et al. 2001; le Noble et al. 2004), which may permit the incorporation of ECs from pruned vessels into other parts of the remodeling vascular network. Whether or not reprogrammed LECs are generated under physiological conditions and incorporated into blood vessels remains open at this point and requires further investigation. Some evidence indicates that LECs can at least dedifferentiate in certain pathobiological processes. In angiosarcoma and Karposi's sarcoma, which are malignant EC cancers, neoplastic cells express both BEC and LEC markers (Breiteneder-Geleff et al. 1999; Hong et al. 2004; Wang et al. 2004). In lymphoedema distichiasis, a hereditary syndrome in which lymphatic drainage is compromised as a consequence of mutations in the human FOXC2 gene, lymphatic vessels in the lower limbs obtain ectopic SMCs, are filled with blood and lack valves (Fang et al. 2000; Kriederman et al. 2003; Petrova et al. 2004). Similar defects can be also seen in Foxc2 mutant mice, and some evidence suggests that Foxc2 may be downstream from Prox1 in LECs (Petrova et al. 2004; Johnson et al. 2008). Expression of Proxl is down-regulated in the dilated and blood-filled intestinal lymphatics of mice that lack fasting-induced adipose factor (FIAF; also known as ANGPTL4) (Backhed et al. 2007). Altered expression or activity of Prox 1 may also play an important role in other mutant mouse models with lymphatic defects such as blood filling, SMC coverage, lack of valves, and shunts between LECs and BECs (Abtahian et al. 2003; Makinen et al. 2005; Foo et al. 2006), which requires further investigation. Conversely, it will be important to identify the upstream factors that control Proxl expression. Such a role has been attributed to interleukin 3, a chemokine that is produced by LECs but not BECs (Gröger et al. 2004), but additional inducers of lymphatic Proxl expression may exist. Prox 1 is a direct target of $\beta$-catenin/TCF signaling in the intestine and promotes colorectal cancer progression (Petrova et al. 2008). The functional roles of the master regulator Proxl cover numerous physiological and pathological processes inside and outside the lymphatic system, which warrants further research and will surely unravel other exciting aspect of Prox1 biology.

\section{Acknowledgments}

We thank the Max-Planck-Society and the University of Münster for their support.

\section{References}

Abtahian, F., Guerriero, A., Sebzda, E., Lu, M.M., Zhou, R., Mocsai, A., Myers, E.E., Huang, B., Jackson, D.G., Ferrari, V.A., et al. 2003. Regulation of blood and lymphatic vascular separation by signaling proteins SLP-76 and Syk. Science 299: 247-251.

Adams, R.H. and Alitalo, K. 2007. Molecular regulation of angiogenesis and lymphangiogenesis. Nat. Rev. Mol. Cell Biol. 8: 464-478.

Alitalo, K., Tammela, T., and Petrova, T.V. 2005. Lymphangiogenesis in development and human disease. Nature 438: 946-953.

Backhed, F., Crawford, P.A., O'Donnell, D., and Gordon, J.I. 2007. Postnatal lymphatic partitioning from the blood vasculature in the small intestine requires fasting-induced adipose factor. Proc. Natl. Acad. Sci. 104: 606-611.

Baluk, P. and McDonald, D.M. 2008. Markers for microscopic imaging of lymphangiogenesis and angiogenesis. Ann. N. Y. Acad. Sci. 1131: 1-12.

Baluk, P., Fuxe, J., Hashizume, H., Romano, T., Lashnits, E., Butz, S., Vestweber, D., Corada, M., Molendini, C., Dejana, E., et al. 2007. Functionally specialized junctions between endothelial cells of lymphatic vessels. J. Exp. Med. 204: 2349-2362.

Breiteneder-Geleff, S., Soleiman, A., Kowalski, H., Horvat, R., Amann, G., Kriehuber, E., Diem, K., Weninger, W., Tschachler, E., Alitalo, K., et al. 1999. Angiosarcomas express mixed endothelial phenotypes of blood and lymphatic capillaries: Podoplanin as a specific marker for lymphatic endothelium. Am. J. Pathol. 154: 385-394.

Cueni, L.N. and Detmar, M. 2006. New insights into the molecular control of the lymphatic vascular system and its role in disease. J. Invest. Dermatol. 126: 2167-2177.

Dejana, E. 2004. Endothelial cell-cell junctions: Happy together. Nat. Rev. Mol. Cell Biol. 5: 261-270.

Dejana, E., Taddei, A., and Randi, A.M.. 2007. Foxs and Ets in the transcriptional regulation of endothelial cell differentiation and angiogenesis. Biochim. Biophys. Acta 1775: 298312.

Fang, J., Dagenais, S.L., Erickson, R.P., Arlt, M.F., Glynn, M.W., Gorski, J.L., Seaver, L.H., and Glover, T.W. 2000. Mutations in FOXC2 (MFH-1), a forkhead family transcription factor, are responsible for the hereditary lymphedema-distichiasis syndrome. Am. J. Hum. Genet. 67: 1382-1388.

Fischer, A., Schumacher, N., Maier, M., Sendtner, M., and Gessler, M. 2004. The Notch target genes Hey1 and Hey2 are required for embryonic vascular development. Genes \& Dev. 18: 901-911.

Foo, S.S., Turner, C.J., Adams, S., Compagni, A., Aubyn, D., Kogata, N., Lindblom, P., Shani, M., Zicha, D., and Adams, 
R.H. 2006. Ephrin-B2 controls cell motility and adhesion during blood-vessel-wall assembly. Cell 124: 161-173.

Gröger, M., Loewe, R., Holnthoner, W., Embacher, R., Pillinger, M., Herron, G.S., Wolff, K., and Petzelbauer, P. 2004. IL-3 induces expression of lymphatic markers Prox-1 and podoplanin in human endothelial cells. J. Immunol. 173: 71617169.

Hayashi, H. and Kume, T. 2008. Foxc transcription factors directly regulate Dll4 and Hey2 expression by interacting with the VEGF-Notch signaling pathways in endothelial cells. PLoS One 3: e2401. doi: 10.1371/journal.pone.00002401.

Hong, Y.K., Harvey, N., Noh, Y.H., Schacht, V., Hirakawa, S., Detmar, M., and Oliver, G. 2002. Prox1 is a master control gene in the program specifying lymphatic endothelial cell fate. Dev. Dyn. 225: 351-357.

Hong, Y.K., Foreman, K., Shin, J.W., Hirakawa, S., Curry, C.L., Sage, D.R., Libermann, T., Dezube, B.J., Fingeroth, J.D., and Detmar, M. 2004. Lymphatic reprogramming of blood vascular endothelium by Kaposi sarcoma-associated herpesvirus. Nat. Genet. 36: 683-685.

Johnson, N.C., Dillard, M.E., Baluk, P., McDonald, D.M., Harvey, N.L., Frase, S.L., Oliver, G. 2008. Lymphatic endothelial cell identity is reversible and its maintenance requires Proxl activity. Genes \& Dev. (this issue). doi: 10.1101/gad.1727208.

Karkkainen, M.J., Haiko, P., Sainio, K., Partanen, J., Taipale, J., Petrova, T.V., Jeltsch, M., Jackson, D.G., Talikka, M., Rauvala, H., et al. 2004. Vascular endothelial growth factor $\mathrm{C}$ is required for sprouting of the first lymphatic vessels from embryonic veins. Nat. Immunol. 5: 74-80.

Kriederman, B.M., Myloyde, T.L., Witte, M.H., Dagenais, S.L., Witte, C.L., Rennels, M., Bernas, M.J., Lynch, M.T., Erickson, R.P., Caulder, M.S., et al. 2003. FOXC2 haploinsufficient mice are a model for human autosomal dominant lymphedema-distichiasis syndrome. Hum. Mol. Genet. 12: 1179-1185.

Lamont, R.E. and Childs, S. 2006. MAPping out arteries and veins. Sci. STKE 2006: pe39. doi: 10.1126/stke.3552006pe39.

Lee, S., Kang, J., Yoo, J., Ganesan, S.K., Cook, S.C., Aguilar, B., Ramu, S., Lee, J., and Hong, Y.K. 2008. Prox1 physically and functionally interacts with COUP-TFII to specify lymphatic endothelial cell fate. Blood doi: Blood-2008-03-145789v1.

le Noble, F., Moyon, D., Pardanaud, L., Yuan, L., Djonov, V., Matthijsen, R., Breant, C., Fleury, V., and Eichmann, A. 2004. Flow regulates arterial-venous differentiation in the chick embryo yolk sac. Development 131: 361-375.

Makinen, T., Adams, R.H., Bailey, J., Lu, Q., Ziemiecki, A., Alitalo, K., Klein, R., and Wilkinson, G.A. 2005. PDZ interaction site in ephrinB2 is required for the remodeling of lymphatic vasculature. Genes \& Dev. 19: 397-410.

Moyon, D., Pardanaud, L., Yuan, L., Breant, C., and Eichmann, A. 2001. Plasticity of endothelial cells during arterial-venous differentiation in the avian embryo. Development 128: 3359-3370.

Odaka, C., Morisada, T., Oike, Y., and Suda, T. 2006. Distribution of lymphatic vessels in mouse thymus: Immunofluorescence analysis. Cell Tissue Res. 325: 13-22.

Petrova, T.V., Makinen, T., Makela, T.P., Saarela, J., Virtanen, I., Ferrell, R.E., Finegold, D.N., Kerjaschki, D., Yla-Herttuala, S., and Alitalo, K. 2002. Lymphatic endothelial reprogramming of vascular endothelial cells by the Prox-1 homeobox transcription factor. EMBO J. 21: 4593-4599.

Petrova, T.V., Karpanen, T., Norrmen, C., Mellor, R., Tamakoshi, T., Finegold, D., Ferrell, R., Kerjaschki, D., Mortimer, P., Yla-Herttuala, S., et al. 2004. Defective valves and abnormal mural cell recruitment underlie lymphatic vascular failure in lymphedema distichiasis. Nat. Med. 10: 974-981.

Petrova, T.V., Nykanen, A., Norrmen, C., Ivanov, K.I., Andersson, L.C., Haglund, C., Puolakkainen, P., Wempe, F., von Melchner, H., Gradwohl, G., et al. 2008. Transcription factor PROX1 induces colon cancer progression by promoting the transition from benign to highly dysplastic phenotype. Cancer Cell 13: 407-419.

Roca, C. and Adams, R.H. 2007. Regulation of vascular morphogenesis by Notch signaling. Genes \& Dev. 21: 2511-2524.

Seo, S., Fujita, H., Nakano, A., Kang, M., Duarte, A., and Kume, T. 2006. The forkhead transcription factors, Foxc1 and Foxc2, are required for arterial specification and lymphatic sprouting during vascular development. Dev. Biol. 294: 458470.

Srinivasan, R.S., Dillard, M.E., Lagutin, O.V., Lin, F.J., Tsai, S., Tsai, M.J., Samokhvalov, I.M., and Oliver, G. 2007. Lineage tracing demonstrates the venous origin of the mammalian lymphatic vasculature. Genes \& Dev. 21: 2422-2432.

Veikkola, T., Jussila, L., Makinen, T., Karpanen, T., Jeltsch, M., Petrova, T.V., Kubo, H., Thurston, G., McDonald, D.M., Achen, M.G., et al. 2001. Signalling via vascular endothelial growth factor receptor-3 is sufficient for lymphangiogenesis in transgenic mice. $E M B O$ J. 20: 1223-1231.

Wang, H.W., Trotter, M.W., Lagos, D., Bourboulia, D., Henderson, S., Makinen, T., Elliman, S., Flanagan, A.M., Alitalo, K., and Boshoff, C. 2004. Kaposi sarcoma herpesvirus-induced cellular reprogramming contributes to the lymphatic endothelial gene expression in Kaposi sarcoma. Nat. Genet. 36: 687-693.

Wigle, J.T. and Oliver, G. 1999. Prox1 function is required for the development of the murine lymphatic system. Cell 98: 769-778.

Wigle, J.T., Harvey, N., Detmar, M., Lagutina, I., Grosveld, G., Gunn, M.D., Jackson, D.G., and Oliver, G. 2002. An essential role for Proxl in the induction of the lymphatic endothelial cell phenotype. EMBO J. 21: 1505-1513.

Wilting, J., Papoutsi, M., Christ, B., Nicolaides, K.H., von Kaisenberg, C.S., Borges, J., Stark, G.B., Alitalo, K., Tomarev, S.I., Niemeyer, C., et al. 2002. The transcription factor Prox1 is a marker for lymphatic endothelial cells in normal and diseased human tissues. FASEB J. 16: 1271-1273.

You, L.R., Lin, F.J., Lee, C.T., DeMayo, F.J., Tsai, M.J., and Tsai, S.Y. 2005. Suppression of Notch signalling by the COUP-TFII transcription factor regulates vein identity. $\mathrm{Na}$ ture 435: 98-104. 


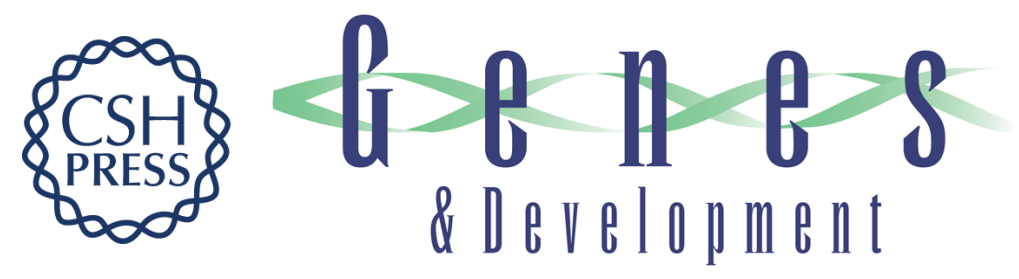

\section{Master and commander: continued expression of Prox1 prevents the dedifferentiation of lymphatic endothelial cells}

M. Gabriele Bixel and Ralf H. Adams

Genes Dev. 2008, 22:

Access the most recent version at doi:10.1101/gad.1751908
Related Content
Lymphatic endothelial cell identity is reversible and its maintenance requires Prox1 activity
Nicole C. Johnson, Miriam E. Dillard, Peter Baluk, et al.
Genes Dev. December, 2008 22: 3282-3291
References This article cites 37 articles, 15 of which can be accessed free at:
http://genesdev.cshlp.org/content/22/23/3232.full.html\#ref-list-1
Articles cited in:
http://genesdev.cshlp.org/content/22/23/3232.full.html\#related-urls

\section{License}
Email Alerting
Service
Receive free email alerts when new articles cite this article - sign up in the box at the top right corner of the article or click here.

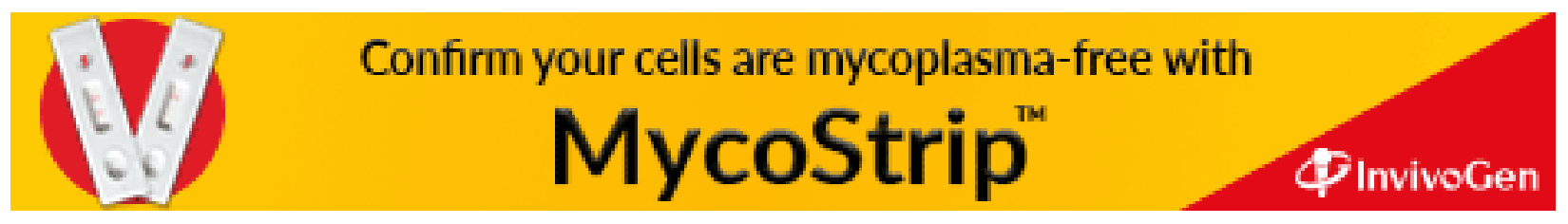

